\title{
Visible spatial contiguity of social information and reward affects social learning in brown capuchins (Sapajus apella) and children (Homo sapiens)
}

Lara A. Wood and Andrew Whiten

This is the accepted manuscript (C) 2017, APA.

This article may not exactly replicate the final version published in the APA journal. It is not the copy of record.

The published article is available from: http://www.apa.org/pubs/journals/com/ 
Accepted in the Journal of Comparative Psychology on 12 April 2017

1 Visible spatial contiguity of social information and reward affects social learning in

2

3

4

5

6

$7{ }^{1}$ Centre for Social Learning and Cognitive Evolution, and Scottish Primate Research Group, 8

\author{
Lara A Wood ${ }^{1,2} \&$ Andrew Whiten ${ }^{1}$ \\ ${ }^{1}$ University of St Andrews, ${ }^{2}$ University of Abertay
}

2 Division of Psychology, Abertay University, Dundee, DD1 1HG

E-mail: 1anw@st-andrews.ac.uk (corresponding author)

Author Note: This work was supported by a John Templeton Foundation grant ID 40128 awarded to A Whiten \& K Laland.

\section{Acknowledgements}

This research was undertaken at Edinburgh Zoo and we thank The Royal Zoological Society of Scotland, their employees based at Budongo and Living Links, and the visitors for their cooperation. Thank you to Hugo Jeffries for assistance with the child study and a volunteer research assistant for inter-rater coding, Lewis Dean, Samantha Allan, and Alison Milne for coding, and Keith Haynes for manufacture of the apparatus. Thank you to the editor and reviewers for their helpful comments. 
Accepted in the Journal of Comparative Psychology on 12 April 2017

\section{Abstract}

25 Animal social learning is typically studied experimentally by the presentation of artificial 26 foraging tasks. Although productive, results are often variable even for the same species. We

27 present and test the hypothesis that one cause of variation is that spatial distance between

28 rewards and the means of reward release causes conflicts for participants' attentional focus.

29 We investigated whether spatial contiguity between a visible reward and the means of release would affect behavioral responses that evidence social learning, testing 21 brown capuchins

31 (Sapajus apella), a much studied species with variant evidence for social learning, and 180

32 two- to four-year old human children (Homo sapiens), a benchmark species known for a

33 strong social learning disposition. Participants were presented with a novel transparent apparatus where a reward was either proximal or distal to a demonstrated means of releasing it. A distal reward location decreased attention towards the location of the demonstration and impaired subsequent success in gaining rewards. Generally, the capuchins produced the

37 alternative method to that demonstrated whereas children copied the method demonstrated, although a distal reward location reduced copying in younger children. We conclude that some design features in common social learning tasks may significantly degrade the evidence for social learning. We have demonstrated this for two different primates but suggest that it is

41 a significant factor to control for in social learning research across all taxa.

42

43 Keywords: Social learning mechanisms, Attention, Spatial contiguity 
Accepted in the Journal of Comparative Psychology on 12 April 2017

\section{Visible spatial contiguity of social information and reward affects social learning in} brown capuchins (Sapajus apella) and children (Homo sapiens)

The formation of social traditions and culture in animal societies relies on the social transmission of information among individuals in a group. Many cognitive mechanisms exist that might facilitate the transmission of information from one individual to another (Heyes, 1994; Whiten, Horner, Litchfield, \& Marshall-Pescini, 2004) and understanding these mechanisms is integral to understanding species differences in cultural abilities. Whiten et al's. (2004) taxonomy of social learning mechanisms in primates details a plethora of ways in which social learning might occur with different mechanisms involving differing levels of cognitive complexity. For example, Whiten et al. (2004) define imitation as copying the form of an action (model movement centred), object movement re-enactment as copying the form of a caused object movement (object movement centred), and end-state-emulation as copying only the end or outcome of an action sequence (outcome centred). Refinements in empirical methods and experimental tasks have aided the identification of social learning and the corresponding mechanisms. One key experimental tool is artificial foraging apparatuses, with two-action apparatuses offering a powerful design for measuring social learning. First implemented by Dawson and Foss (1965) with budgerigars, these apparatuses offer two or more means of accessing a reward (henceforth shortened to means) held within a defense component that may occur in natural foods such as shelled fruits and insects within nests. Control subjects are given such a task without any social information. Their behavior serves as a baseline and is compared to other individuals' behavior following observation of either of the alternative approaches. Social learning can be evidenced by increased levels of success, decreased latency to success, or matching the means demonstrated. 
Accepted in the Journal of Comparative Psychology on 12 April 2017

In the last decade such apparatuses have been used in taxa from birds (Alpin et al., 2015) to meerkats (Thornton \& Malapert, 2009), primate species including chimpanzees (Whiten, Horner, \& de Waal, 2005), squirrel monkeys (Claidière, Messer, Hoppitt, \& Whiten, 2013), vervet monkeys (van de Waal, Renevey, Favre, \& Bshary, 2010) as well as human children (Horner \& Whiten, 2005) and adults (Flynn \& Smith, 2012). However, within- and cross-species comparisons of social learning can be elusive due to variation in the different apparatuses' manifestations, which can vary in their (1) means (2) degree of transparency, (3) model type, and (4) efficiency (see Figure 1 for an illustration of these differences). Thus, identifying the copying of a model's movement ('imitation'; Whiten \& Ham, 1994) may be restricted to tasks where the same component is moved but by different model actions (Figure 1(1c)), or through the use of a ghost condition (Figure 1(3b) e.g., Hopper, Lambeth, Schapiro, \& Whiten, 2008). Given the theoretical assertion that mechanisms such as imitation may be unique to humans (Tomasello, 1996), it is important that the social learning capabilities of each species are correctly identified.

For some species the evidence for social learning capabilities is still extremely variable. For example, capuchins (Cebus and Sapajus genus) belonging to the Cebidae family display strong social bonds, tool-use in the wild, and evidence of complex social traditions (Fragaszy, Visalbergi, \& Fedigan, 2004; Perry et al., 2003; Perry, 2011) and yet huge variation exists in experimental evidence for social learning in this genus (e.g., Dindo, Thierry, de Waal, \& Whiten, 2010 versus Fragaszy \& Visalberghi, 1989). Here we explore the hypothesis that some of these differences have been caused by variations in the apparatuses presented, specifically in regard to the spatial contiguity of the reward, the means, and the consequent social information as it affects the means. Capuchins' natural attentional disposition may direct them towards rewards, making them less attentive to important social information distal to these rewards. In the wild capuchins may be attracted 
Accepted in the Journal of Comparative Psychology on 12 April 2017

to, for example, a nut protected by an opaque defense (the shell). These elements, the nut and the shell, are directly proximal to each other. If a conspecific demonstrated breaking the defense and acquiring the nut, for example by hitting the shell with a stone hammer, the model's actions and the means (shell breaking) are also proximal. In contrast, the form of some apparatuses is such that the reward is visible (the apparatus is transparent) and the means is not immediately proximal to the reward (Custance, Whiten, \& Fredman, 1999; Fragaszy \& Visalberghi, 1989; Visallberghi, 1993). Accordingly, attention may be drawn to the reward rather than to the social information, potentially impairing social learning. Spatial contiguity has been long thought of as a factor affecting non-social associative learning in animals. Proximal unconditioned stimuli (often a food reward) and conditioned stimuli (akin to the means) aid conditioning and discrimination learning (Wasserman \& Miller, 1997). Rhesus macaques, for example, fail to learn a series of pattern of discrimination problem when required to make their instrumental response at a distal location from the stimulus but are successful when the two are proximal (Polidora \& Fletcher, 1964). Similarly, two- and young three-year-old human children struggle to understand a causal relationship between an action and an outcome when the two are distal, but succeed when the two are proximal (Kushnir \& Gopnik, 2007). Interestingly, three and four-year-old children were successful in both conditions, suggesting a developmental shift in the understanding of a causal event distally located from an action.

Another factor that might decrease success in tasks that have a distal spatial contiguity between means and rewards is prepotent responses to attend to and reach for food, associated with a lack of inhibitory control. Capuchins, described as an impulsive species (Fragaszy et al., 2004), have relatively poor inhibitory control as compared with other largebrained primates (Amici, Aureli, \& Call, 2008). Task-naïve capuchins show little evidence of self-control concerned with delay gratification (Beran et al., 2016) although with training 
Accepted in the Journal of Comparative Psychology on 12 April 2017

118 they can develop delay gratification and let lesser rewards pass them by in order to obtain

119 greater rewards (Bramlett, Perdue, \& Evans, 2012). Furthermore, capuchins can also learn to

120 use a computer joystick where their actions (operating the joystick) are necessarily spatially

121 distal from the movement of the cursor (Evans, Beran, Chan, Klein, \& Menzel, 2008).

122 Therefore, we might expect to see an improvement in performance over multiple trials and

123 phases when using distally presented rewards.

124 Taking such considerations into account in the context of social learning, we may

125 predict more learning in capuchins when the distance between reward and the action upon

126 the defense are proximal or unknown. Conversely, we would predict depleted evidence of

127 social learning when the reward and action upon the defense are visibly distal. Dindo,

128 Thierry, de Waal, \& Whiten (2010) created an opaque apparatus in which either one food reward was baited behind a central door-defense that could be removed up, either diagonally left or right (Experiment 1), or two food rewards each baited behind two defenses that could

131 be accessed by moving a slider up either diagonally left or right (Experiment 2). Copying of

132 the means (door left or right) was evident in Experiment 1 but relatively absent in

133 Experiment 2. The authors concluded that the different responses may have been due to the capuchins prioritizing exploratory behavior when alternative foraging locations were accessible. An alternative explanation is that the reward locations affected the capuchins' attention: in Experiment 1 attention was directed towards the reward behind the central door

137 and this door's movement was salient, whereas in Experiment 2 attention was directed

138 towards the rewards behind the two top defences and the central door movement was less salient. Thus opacity of reward location may facilitate social learning. 


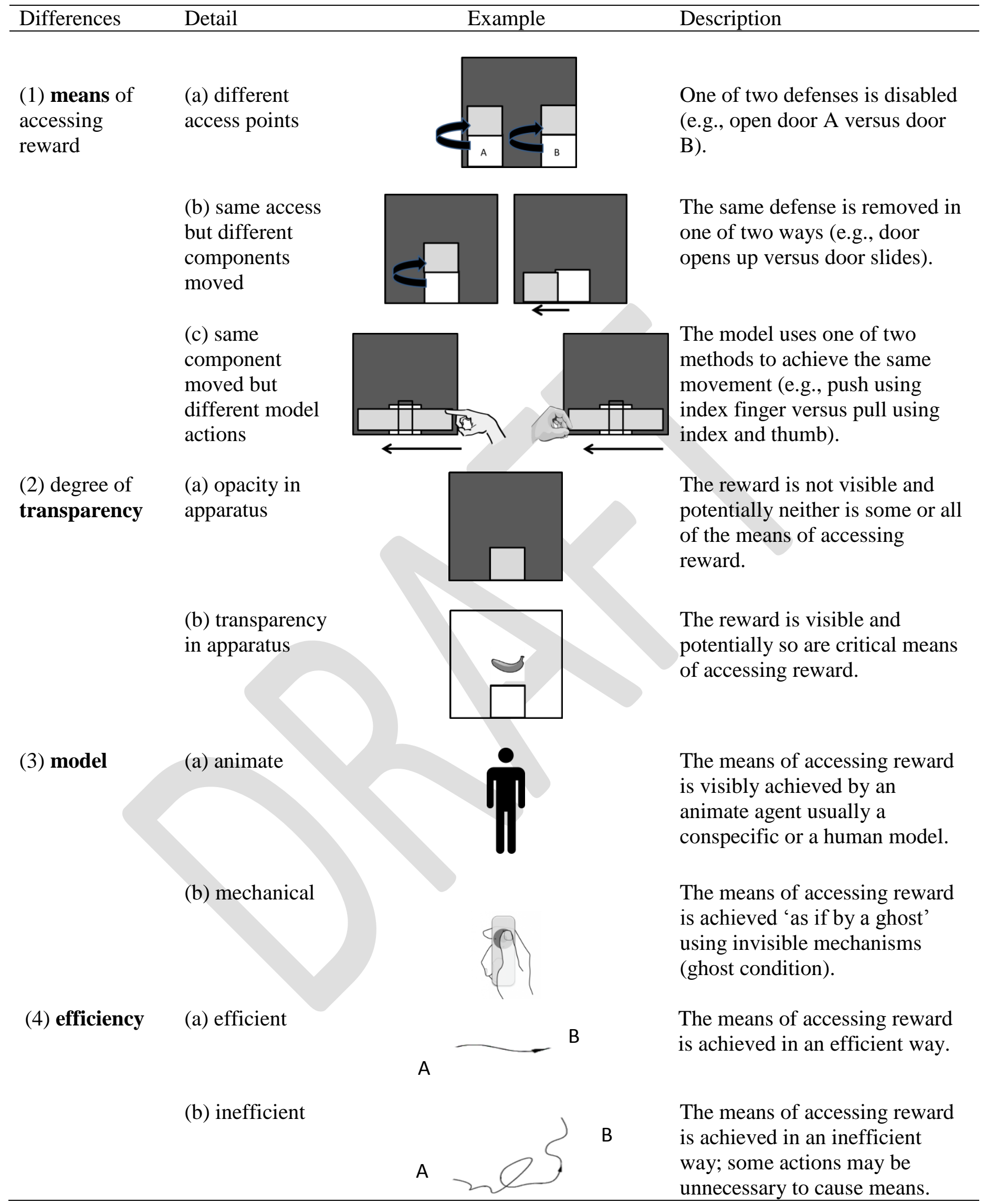

140 Figure 1: Schematic overview of ways in which apparatuses can differ. 
Accepted in the Journal of Comparative Psychology on 12 April 2017

There are empirical examples of opaque defense configurations, such that the

142 distance between the reward and actions upon the defense are also opaque. Crast, Hardy \&

143 Fragaszy (2010) created a task for tufted capuchins (Sapajus apella) involving opaque juice

144 dispensers offering two different methods of solution. Here, infants' learning was assisted by

145 the demonstration of successful juice extraction by adults. There was some evidence of

146 preferential copying of the specific method seeded although this was confounded by the

147 locking of the alternative method during a phase of the experiment. Dindo, Thierry, \&

148 Whiten (2008) and Fredman \& Whiten (2008) created a number of opaque apparatuses that

149 included a single defense that could be operated in either of two different ways and in both

150 studies there was significant matching to the method witnessed, possibly by emulation of the

151 means (e.g., lift door versus slide door). Fredman \& Whiten (2008) included a study where

152 humans demonstrated a tool-use behavior to human-reared capuchins. Here, some evidence

153 existed that capuchins copied the model's actions as well as the result. Fredman \& Whiten

154 (2008) suggest that the enculturation experience of these capuchins may have elevated

155 cognitive processes to facilitate imitation or other relatively sophisticated social learning

156 mechanisms. However, differences in demonstration from humans versus conspecifics

157 cannot be discounted as explanations for the differences in learning between the human-

158 raised and mother-raised capuchins.

159 In contrast to such opaque apparatuses, some studies have employed transparent tasks

160 with a distal location between reward and actions upon the defense and these have elicited

161 very little evidence of social learning. Fragaszy \& Visalberghi (1989) presented two different

162 apparatuses to two groups of tufted capuchins. Both apparatuses had visible rewards and

163 required the use of tools. Several capuchins in each group learned to solve these problems

164 but the analysis of conspecific observations and order of success did not provide any

165 evidence of the capuchins learning about specific instrumental relations. Likewise, 
Accepted in the Journal of Comparative Psychology on 12 April 2017

166 Visalberghi (1993) presented six capuchin monkeys with sticks and a transparent, baited

167 tube. Three spontaneously solved the task but the other three, despite opportunity to watch successful conspecifics, were not successful. Analysis of videos revealed that the capuchins did not selectively scrutinise the actions of the model while s/he solved the problem anymore than in non-demonstration periods. It should be noted that these tasks also required tool use which may have impacted success. Custance et al. (1999) employed two versions of a transparent apparatus, incorporating either a barrel or bolt latch, each of which could be opened with either of two techniques consisting of two related actions. The reward was visible at the bottom of the apparatus although it was not placed in a specific area (Fredman, personal communication) and the defenses were situated at the top section of the apparatus. In the bolt latch task the capuchins used the demonstrated technique and the non-demonstrated technique at equivalent frequencies and coders were unable to infer which technique the capuchins had seen demonstrated. Likewise, the two techniques for the bolt latch were used at equivalent

180 frequencies irrespective of demonstration content, although here coders were able to infer

181 which technique had been demonstrated based on whether the capuchin's actions occurred in the front or the back of the apparatus.

In summary, capuchin social learning has appeared most evident and sophisticated when the distance between reward and means were proximal or unknown. These findings support the hypothesis that visible contiguity between reward and social information affects social learning. The current study directly tested this hypothesis by systematically manipulating the proximity between a reward and the social information. We predicted that the location of the reward would affect capuchin performance on the task such that a reward that was distal, as opposed to proximal to the task, would: (a) reduce attention toward the 
Accepted in the Journal of Comparative Psychology on 12 April 2017

190

191

192

193

194

195

196

197

198

199

200

201

202

203

204

205

206

207

208

209

210

211

212

213

214

means as the capuchins would look significantly more at the reward; (b) reduce success and latency to success; (c) reduce copying of demonstrated means.

\section{A comparative study with human children}

We have focused the above analysis and the present study on capuchin monkeys because our general hypothesis may explain the huge variability in evidence for social learning in this genus. However, as previously discussed, effects of spatial continuity on learning are evident in other animals. Here we chose to explore the issue further with a second primate species, humans. Human children are prolific social learners from infancy (Carpenter, Akhtar, \& Tomasello, 1998) and the importance of attention for children's social learning has long been highlighted (Bandura \& Walters, 1977). Children can provide a good comparative group for understanding phenomena relating to social learning because unlike many captive primate populations one can access a large sample size allowing for: (a) additional experimental conditions; (b) the study of a large sample, within a restricted age period, to capture developmental changes in the phenomena of interest; (c) the inclusion of additional control conditions excluding the demonstration of social information. The current study involved 180 two- to four-year-old children alongside 21 capuchins.

In the last two decades there has been a surge of experiments with children utilizing foraging apparatuses, with stickers often replacing food rewards (e.g., Horner \& Whiten 2005; Wood, Harrison, Lucas, McGuigan, Burdett, \& Whiten, 2016). These apparatuses have evidenced sophisticated social learning in children that extends to high fidelity copying of demonstrator actions and results (Hopper, Flynn, Wood, \& Whiten, 2010). For the current study two- to four-year-olds were selected as there are important developmental changes in social learning mechanisms during these ages. For example, following video demonstrations of the removal of a reward, situated $15 \mathrm{~cm}$ behind an opaque defense, five-year-old children 
Accepted in the Journal of Comparative Psychology on 12 April 2017

215 faithfully copied all actions, whereas three-year-olds omitted significantly more of the unnecessary actions (McGuigan, Whiten, Flynn, \& Horner, 2007). Exploring the effect of

217 spatial contiguity in a similar apparatus should inform our understanding of the impact of 218 distracting rewards upon social learning.

Development of children's cognitive skills may affect their attention to reward, rather than means. For example, four-year-olds show substantially more settled and focused attention than two-year-olds (Anderson \& Levin, 1976; Ruff \& Capozzoli, 2003). They can therefore focus on multiple stimuli and be less distracted by other attractive stimuli. Ruff \& Capozzoli (2003) suggest inhibitory control processes were present in the older, but not the younger, children. Indeed, there is a significant increase in children's inhibitory control abilities from two- to four-years-old (Kochanska, Murray, Jacques, Koenig, \& Vandegeest, 1996). We tested 60 children on their response to the apparatus without showing them social information to ascertain a baseline of success (we also did this for two male capuchins that would not isolate). Half of the control children were presented with the task with the reward and means distally located, half with them proximally located. We predicted less success and greater latency to success for children in the distal as opposed to the proximal condition. For the 120 children that watched demonstrations we predicted that, as with the capuchins, a reward that was distal, as opposed to proximal, to the means would: (a) reduce attention toward the means as the children would look significantly more at the reward; (b) reduce

234 success and latency to success; (c) reduce copying of the demonstrated means. Further, in 235 line with improvement in attention and inhibitory control, we predicted that this effect would be least pronounced in the older children. 
Accepted in the Journal of Comparative Psychology on 12 April 2017

Experiment 1: Capuchins

239

\section{Study site and participants}

Participants were housed at the Living Links to Human Evolution Research Centre, based within the Royal Zoological Society of Scotland's Edinburgh Zoo, UK (Leonardi et al., 2010; MacDonald \& Whiten, 2011). Accordingly, all procedures were approved by the Royal Zoological Society of Scotland as well as the Ethics Committee of the University of St Andrews' School of Psychology. Procedures were conducted in accordance with the guidelines of the Association for the Study of Animal Behaviour. The Centre houses two mixed species communities of common squirrel monkeys (Saimiri sciureus) and brown (tufted) capuchin monkeys (Sapajus apella) in two neighboring enclosures. At the time of the experiment, there were nine adult males, seven adult females, seven sub-adults, six juveniles and six infants. The groups were housed in similar enclosures comprised of a $900 \mathrm{~m}^{2}$ outdoor area containing vegetation and a $189 \mathrm{~m}^{3}$ indoor enclosure. The monkeys have 24 hour indoor and outdoor access (excepting inclement weather) including access to an off-exhibit indoor area. The monkeys are given a rich diet of meat, eggs, fruit, vegetables and TrioMunch pellets and have access to water ad libitum except for periods of voluntary isolation in the research cubicles, which involve a maximum of two 15 min periods on four days of the week. Most of the monkeys are habituated to remain in the research cubicles for research sessions by themselves. Entrance into the research cubicles is voluntary and a monkey is never forced to come into the research cubicles. If a monkey shows any signs of distress including ceasing participation, moving to the back of the cubicle, putting hands on the cubicle slides and/or specific vocalisations, they are reintroduced to the group immediately. Rewards used in experiments are sunflower seeds, nuts, raisins, dates, cereal and mealworms. Maximum allowances for these are specified by the husbandry team. 
Accepted in the Journal of Comparative Psychology on 12 April 2017

Participants aged over one-year-old $(\mathrm{N}=33)$ were invited into research cubicles (described below). Of the thirty-three potential participants 22 animals voluntarily separated to participate but three of these showed signs of anxiety during the demonstration phase and so did not continue with the experiment leaving 19 capuchins that participated in the full experiment. These capuchins ranged from three to 17 years-old. Nine capuchins (three females, Mean age $=8.8(\mathrm{SD}=4.4)$ years $)$ were in the proximal condition and ten capuchins (three females, Mean age $=6.5(\mathrm{SD}=3.3)$ years $)$ were in the distal condition. Two additional adult males would not separate from the group but were able to monopolise the apparatus and so participated at the end. They served as no-demonstration controls, receiving no information before being given access to the task.

\section{Design}

In a between-group design capuchins were systematically assigned, dependent on their age and sex, to one of two experimental conditions in which the food reward was placed in either a proximal $(5 \mathrm{~cm})$ or distal $(25 \mathrm{~cm})$ location relative to the means. Capuchins watched either a pull-cord or lift-platform method of reward retrieval as described below, counterbalanced across the experimental condition. Finally, as a quasi within-subject control the reward location was reversed in a second phase creating an additional within-subject variable of reward location.

\section{Materials}

A new apparatus was created for this experiment to meet three criteria not met in preexisting apparatus: (a) the apparatus had two distinctly different means of accessing a single reward; (b) the reward could be moved so as to manipulate the distance between the reward and the means; (c) the reward would always be equidistant from the two means. The 
Accepted in the Journal of Comparative Psychology on 12 April 2017

287

288

289

290

291

292

293

294

295

296

297

298

299

300

301

302

303

304

305

306

307

308

309

310

apparatus (see Figure 2) was a transparent plastic cuboid case $(1=30 \mathrm{~cm}, \mathrm{~h}=10 \mathrm{~cm}, \mathrm{~d}=$ $8 \mathrm{~cm})$. Within the case there was a transparent platform situated $4 \mathrm{~cm}$ from the top that ran the length of the case. The platform was hinged so the platform could swing up like a flap. The reward could be placed at either end of this platform. There were two means of acquiring the reward. The first means was pull-cord: on the right-hand-side of the platform a cord was threaded from the base of the platform to the top of the case and through a plastic knobble which sat at the top of the box. Thus, when this knobble was pulled up, the cord pulled the platform up, so the reward rolled off the back. The length of this cord prevented the platform from rotating downwards. The second means was lift-platform: below the platform was a $3 \mathrm{~cm}^{2}$ square hole such that the platform could be pushed up from below, again making the reward roll off the back. The released reward fell to the bottom of the front of the transparent case where there was a rectangular hole $(1=26 \mathrm{~cm}, \mathrm{~h}=2 \mathrm{~cm})$ through which the reward exited the case. At the back of the case was a door to allow re-baiting.

Testing took place in one of eight neighboring research cubicles (each approximately $50 \mathrm{~cm} \times 50 \mathrm{~cm} \times 50 \mathrm{~cm})$. At the front of each research cubicle was a window with six holes; one circular $(\mathrm{d}=3 \mathrm{~cm})$ hole in the centre of the window where all rewards could be given by the experimenter, and five holes corresponding with specific locations on the task when it was flush against the window. These included a rectangular formation of four round $(\mathrm{d}=$ $3 \mathrm{~cm}$ ) holes: hole $\mathrm{A}$ in line with the knobble at the top of the task, just above food reward in proximal condition; hole B in line with the opening below the platform, just below food in proximal condition; hole $\mathrm{C}$ same height as hole $\mathrm{A}$ but located $15 \mathrm{~cm}$ away, just above food in distal condition; hole D same height as hole B but located $15 \mathrm{~cm}$ away, just below food in distal condition. The final hole was rectangular with the same dimensions as the exit and lined up with this exit when the box was flush against the window. A Sony Handycam was 
positioned on a tripod behind the task facing towards the capuchins so that their behavior,

\section{Distal}
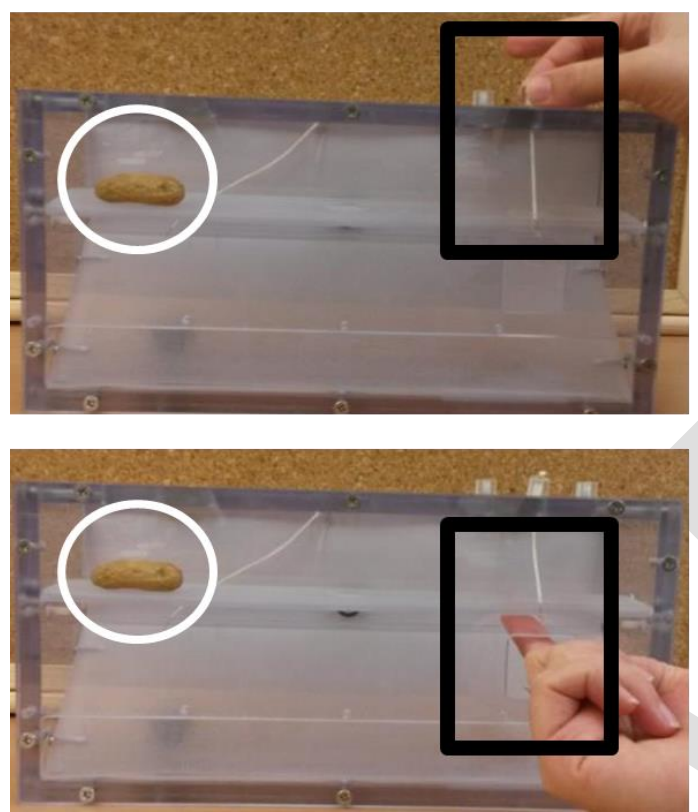

\section{Proximal}
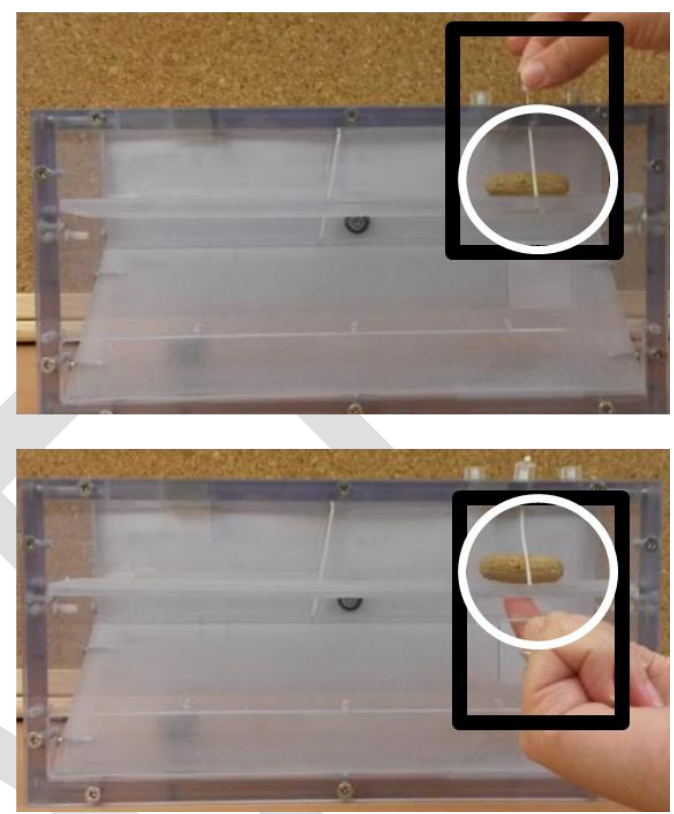

314

315

316

317

318

319

320

321

322

323

324

325

326

327

328

Figure 2. The test apparatus. The reward (highlighted by a white circle) was either distal (left images) or proximal (right images) to the two means. The two means are highlighted by a black rectangle: (1) 'pull-cord' (top images): a plastic knobble joined to the platform by string. Pulling knobble causes the platform to rotate up, and the reward to fall from the back of the platform to the case exit; (2) 'lift-platform': a square hole in the front of the case. Inserting finger through hole and pushing platform causes platform to rotate up, and the reward to fall from the back of the platform to the case exit.

\section{Procedure}

Capuchins were isolated opportunistically depending on cubicle entry and willingness to isolate. Once isolated the capuchin was rewarded with a seed from each of four holes from which they could potentially access the task or attempt to access the food.

The trolley with the task was pulled to within $30 \mathrm{~cm}$ of the front of the window so the capuchin could see the task but not touch it. Once the capuchin was attending to the front the 
Accepted in the Journal of Comparative Psychology on 12 April 2017

329 experimenter said the capuchin's name while simultaneously holding up a reward just above

330 the centre of the task. The experimenter then baited the box, putting the reward in either a

331 proximal or distal location. Within two seconds the experimenter operated either the pull-

332 cord or lift-platform method, such that the platform swung up and the reward fell out of the

333 apparatus and into a tray below, making it clear that the reward had been extracted. The

334 capuchins received 10 demonstrations. On demonstrations one, four, seven, and 10 the nut

335 was taken from the tray and given to the capuchin through the central reward hole. These

336 reward intervals were selected to sustain interest and to indicate that they could receive the

337 reward. A peanut was not given after each trial to avoid satiation and exceeding the zoo's

338 recommend daily amounts (presuming the capuchin gained all rewards in the phase).

339 After the 10 demonstrations the experimenter re-baited the task in the same way and

340 pushed the task forward until it was against the window and the session time of five minutes

341 started. If a capuchin was successful it was given up to a further four trials within five

342 minutes. Capuchins that were not successful were given much lower value rewards through

343 the central hole, including a sunflower seed every minute and two nuts at the end of the

344 session. This was to adhere to facility requirements of promoting isolation and participation

345 in the research cubicles. There was a second phase up to six days later with no

346 demonstrations. The reward was baited in the opposite end of the task for each capuchin. If

347 the capuchin was successful it was given up to a further four trials if this fell within five

348 minutes.

350 Coding

351 Four people (two individuals unaware of the study's aims, one person not involved in

352 the study but aware of the broad hypothesis, and the experimenter) separately coded visual

353 attention for each of the ten trials at the point at which either the pull-cord or lift-platform 
Accepted in the Journal of Comparative Psychology on 12 April 2017

354

355

356

357

358

359

360

361

362

363

364

365

366

367

368

369

370

371

372

373

374

375

376

377

action was performed. Coders were separately asked to imagine a line in the middle of the apparatus and judge, at the moment at which the platform was most raised and the reward fell, whether attention was towards: (a) the left side of the box, where the means were located (means); (b) at the right side of the box, away from the means (non- means); (c) away from the box (away); or (d) unsure of where attention was focused (unsure). If fewer than three coders agreed on a category, this was coded as unsure. All other behaviors were coded by one of the individuals unaware of the study's aims and these included: (a) the side of the box where the participant's hand first made contact with the box (First Touch: means or non-means); (b) successful retrieval of the reward within the trial time (Success: yes or no); (c) duration between the task being pushed flush to the cubicle window and the reward exiting the box (Latency to success); and (d) how the reward was obtained (Means: pullstring, lift-platform or other).

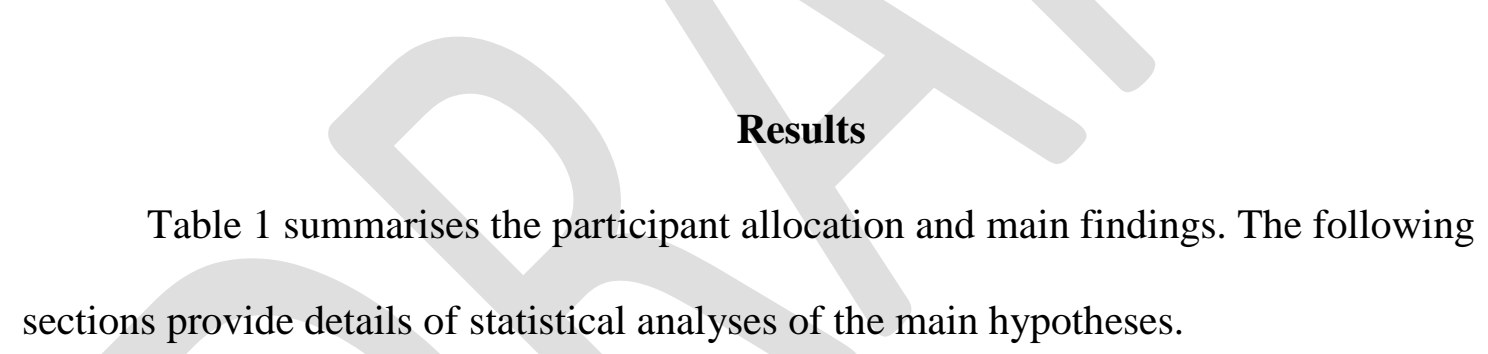

\section{Attention towards means demonstrations}

Stepwise multiple regressions were conducted to evaluate whether visual attention during demonstrations could be predicted by the reward location and the age of the capuchin (Table 2). The count of a capuchin's attention over the ten trials and the capuchin's age were entered separately for attention towards the means and non-means with age and reward location as predictor variables. For both attention towards the means and non-means, the model accounting for significantly more variance than no predictors included just reward 
Accepted in the Journal of Comparative Psychology on 12 April 2017

378 location; with a distal reward location predicting a greater number of looks toward means ( $p$

$379<.001)$ and looks away from means $(p<.01)$.

380

381 Effects of reward contiguity on success

Ten capuchins used pull-cord and eight capuchins used lift-platform for their first success, indicating no bias towards either method (Binomial, $p=.82$, all non-parametric tests are two-tailed). Three of the 19 capuchins, all in the distal condition $(\mathrm{N}=10)$, were unsuccessful. This $30 \%$ failure rate was not significantly different from the $0 \%$ failure rate of those in the proximal condition $(\mathrm{N}=9$, Fisher's exact, $p=.12)$. Latency to success was investigated with unsuccessful capuchins given a latency of 300s (five minutes). A stepwise linear regression was conducted to evaluate whether reward location and participant age were necessary to predict latency to success. At step 1 of the analysis reward location was entered into the regression $\left(\mathrm{B}=98.66, \mathrm{SE}=46.06, p<.05, \mathrm{~F}_{(1,17)}=4.58, \mathrm{p}<.05\right)$ accounting for $21.3 \%$ of the variance. Age did not enter into the equation $(p=.36)$.

Effects of reward contiguity on matching of demonstrated means

Twelve of the 16 successful capuchins used the alternative means to the one demonstrated (Binomial, $p=.08$ ). Eight of the nine capuchins in the proximal condition used the opposite means to the one demonstrated which was itself significant (Binomial, $p<.05$ ).

397 Four of the seven successful capuchins in the distal condition used the opposite means to the one demonstrated which was not a significant difference (Binomial, $p>.99$ ). 
Accepted in the Journal of Comparative Psychology on 12 April 2017

Table 1: Descriptive summary of participants and main results capuchins and children

\begin{tabular}{|c|c|c|c|c|c|c|c|c|c|c|c|}
\hline & \multicolumn{11}{|c|}{$\tilde{x}$ attendance: } \\
\hline & Condition & $\begin{array}{c}\mathrm{N} \\
\text { (Female) }\end{array}$ & $\begin{array}{l}\text { N saw } \\
\text { pull- } \\
\text { cord }\end{array}$ & $\begin{array}{l}\text { Mean Age in } \\
\text { months (SD) }\end{array}$ & $\begin{array}{l}\text { towards } \\
\text { means }\end{array}$ & $\begin{array}{l}\text { toward non- } \\
\text { means }\end{array}$ & away & $\begin{array}{l}\text { attendance } \\
\text { unsure }\end{array}$ & $\begin{array}{c}\text { N successful } \\
(\%)\end{array}$ & $\begin{array}{l}x \text { latency to } \\
\text { success in } \\
\text { seconds } \\
\text { (IQR) }\end{array}$ & $\begin{array}{c}\mathrm{N} \text { copied } \\
\text { demonstrated } \\
\text { means }\end{array}$ \\
\hline \multirow{2}{*}{$\begin{array}{l}\text { Capuchins with } \\
\text { demonstration }\end{array}$} & Proximal & $9(3)$ & 4 & 94.7 (53.9) & 9 & 0 & 0 & 1 & 9/9 (100\%) & $9(47)$ & $1 / 9$ \\
\hline & Distal & $10(3)$ & 6 & $78(45.4)$ & 1 & 2 & 0 & 5.5 & $7 / 10$ (70\%) & 75 (287) & $3 / 7$ \\
\hline \multirow{2}{*}{$\begin{array}{l}\text { Children with } \\
\text { demonstration }\end{array}$} & Proximal & $60(30)$ & 30 & $41.6(10.4)$ & 9 & 0 & 0 & 0 & $59 / 60$ (98\%) & $8(15)$ & $57 / 59$ \\
\hline & Distal & $60(30)$ & 30 & $41.0(10.8)$ & 6 & 1 & 1 & 2 & $50 / 60$ (83\%) & $15(77)$ & $41 / 50$ \\
\hline \multirow{2}{*}{$\begin{array}{l}\text { Children without } \\
\text { demonstration }\end{array}$} & Proximal & $30(15)$ & & $41.6(9.9)$ & & & & & $18 / 30(60 \%)$ & 70.4 (162) & \\
\hline & Distal & 30 (15) & & $41.8(9.6)$ & & & & & $8 / 30$ (27\%) & 180 (39) & \\
\hline
\end{tabular}

400 Note: Attendance to demonstrations (range of 0 to 10) and latency to success were not normally distributed ( $\tilde{x}=$ median).

401

402 Table 2: Summary of simple regression analyses for variables predicting location of attention during demonstrations

\begin{tabular}{|c|c|c|c|c|c|c|c|c|c|c|c|c|}
\hline & \multicolumn{6}{|c|}{ Capuchins } & \multicolumn{6}{|c|}{ Children } \\
\hline & \multicolumn{3}{|c|}{ Non- means } & \multicolumn{3}{|c|}{ Means } & \multicolumn{3}{|c|}{ Non- means } & \multicolumn{3}{|c|}{ Means } \\
\hline & $B$ & SE B & $\beta$ & $B$ & SE B & $\beta$ & $\mathrm{B}$ & SE B & $\beta$ & $\mathrm{B}$ & SE B & $\beta$ \\
\hline Reward Location & -6.5 & 0.85 & $-0.88^{\star \star \star}$ & 2.70 & .84 & $0.62^{\star \star}$ & -1.80 & 0.29 & $-0.50^{\star \star \star}$ & 2.95 & 0.45 & $0.51^{\star * *}$ \\
\hline Age in years & & & & & & & & & & 0.06 & 0.02 & $0.20^{*}$ \\
\hline $\mathrm{R}^{2}$ & & & .77 & & & .38 & & & .25 & & & .30 \\
\hline $\mathrm{F}$ & & & $58.16^{\star \star *}$ & & & $10.46^{\star *}$ & & & $39.88^{* * *}$ & & & $25.53^{* * *}$ \\
\hline
\end{tabular}

403 Note: ${ }^{\star} p<.05 .{ }^{\star \star} p<.01 .{ }^{* \star *} p<.001$. Reward location; proximal $=1$, distal $=2$ 
Accepted in the Journal of Comparative Psychology on 12 April 2017

404 Additional analyses of behavioral details

405

Table 3 presents descriptive statistics and below is a brief overview of the additional

406

analyses. Two capuchins that would not isolate had a reward baited in the proximal location

407 with no demonstration; one discovered pull-cord in 5s and the other discovered lift-platform

408 in 2s. Including the two no-demonstration capuchins, the first touch of 20/21 capuchins

409 corresponded to the location of the reward (Binomial two-tail, $p<.001$ ). Participants could

410 participate in up to five trials in five minutes; $9 / 9$ capuchins in the proximal condition had

411 five successes whereas only 5/10 capuchins in the distal condition completed five trials. In

412 the second phase, when the location of the reward was reversed for each capuchin (proximal

413 to distal and vice versa), the majority once again touched the side of the task where the

414 reward was located, although six capuchins, originally in the proximal condition, touched the

415 side congruent with the means. All previously successful capuchins were successful again.

416 Two of the three previously unsuccessful capuchins were successful when the reward was

417 moved from distal to proximal, both succeeding in $4 \mathrm{~s}$. The third capuchin did not interact

418 with the task. Eight capuchins used the same method throughout, seven of these used the

419 pull-cord. The remaining twelve capuchins used both methods.

420

421 Table 3: Descriptive summary of additional analyses (capuchins)

\begin{tabular}{cccccccc}
\hline & & Phase 2: Reward location reversed for 5 trials & \multicolumn{2}{c}{$\begin{array}{c}\text { x method choice over } \\
\text { ten trials }\end{array}$} \\
\hline Condition & $\begin{array}{c}\text { First touch } \\
\text { proximal to } \\
\text { means }\end{array}$ & $\begin{array}{c}\text { Five } \\
\text { successes } \\
\text { trials } 1 \text { to } 5\end{array}$ & $\begin{array}{c}\text { First touch } \\
\text { proximal to } \\
\text { means }\end{array}$ & $\begin{array}{c}\text { N successful } \\
\text { in Phase } 2\end{array}$ & $\begin{array}{c}\tilde{x} \text { difference in } \\
\text { latency T1-T6 } \\
(\text { IQR })\end{array}$ & $\begin{array}{c}\text { Pull } \\
\text { String }\end{array}$ & $\begin{array}{c}\text { Lift } \\
\text { Platform }\end{array}$ \\
\hline $\begin{array}{c}\text { Proximal } \\
(\mathrm{N}=11) \\
\text { Distal }\end{array}$ & $11 / 11$ & $11 / 11$ & $5 / 11$ & $11 / 11$ & $-6(51.3)$, & $8(4.5)$ & $2(4.0)$ \\
$(\mathrm{N}=10)$ & $1 / 10$ & $5 / 10$ & $9 / 9$ & $9 / 10$ & $14.5(202.3)$ & $5(8.0)$ & $2(5.5)$ \\
\hline 422
\end{tabular}

422 Note: Proximal condition includes two monkeys with no demonstration. Attendance to demonstrations

423 (range of 0 to 10) and latency to success were not normally distributed ( $\tilde{x}=$ median).

424 
Accepted in the Journal of Comparative Psychology on 12 April 2017

\section{Experiment 2: Children}

\section{Study site and participants}

427 In total 193 two- to four-year-old children completed the study. Thirteen children were excluded from analysis for various reasons (English not first language, technical problems during experiment, or interference by caregiver). The remaining 180 children (90 females) ranged from 24 to 59 months $(M=41.4, S D=10.3)$. Children were recruited while visiting Edinburgh Zoo through a poster which read, "Aged 2 to 4? Win stickers!" Consent was obtained from the child's caregiver, provided they were a parent or grandparent.

\section{Design}

In a between-group design echoing the capuchin study, children were systematically assigned, dependent on their age and sex, to one of two experimental conditions, with the reward being placed in a proximal $(5 \mathrm{~cm})$ or distal $(25 \mathrm{~cm})$ location relative to the means. Following the procedure of Experiment 1, 120 of these children watched ten demonstrations of either the pull-cord or lift-platform method or reward retrieval. An additional 60 children did not see any demonstration.

\section{Materials}

The same apparatus was used, bolted to a small wooden table $(\mathrm{l}=50 \mathrm{~cm}, \mathrm{~h}=40 \mathrm{~cm}, \mathrm{~d}$

$444=40 \mathrm{~cm})$. The reward within the apparatus was a plastic medal $(\mathrm{d}=3 \mathrm{~cm})$ which was then

445 exchanged for an equal sized sticker. Testing took place in a designated child research room at RZSS Edinburgh Zoo. There were two small chairs $(\mathrm{h}=80 \mathrm{~cm})$ in the room; one in front of

447 the task (for the participant), and one by the entrance to the room (for the caregiver). The camera and tripod were adjusted for the height of the child. 
Accepted in the Journal of Comparative Psychology on 12 April 2017

450

451

452

453

454

455

456

457

458

459

460

461

462

463

464

465

466

467

468

469

470

471

472

473

474

\section{Procedure}

After obtaining written consent from the caregiver and verbal consent from the child, the child and caregiver were invited into the research room. Additional members of the child's visiting group were asked to remain outside. Children were asked to take a seat on the chair in front of the task and the experimenter knelt down to be at a similar height to the child. The table with the task was located within $20 \mathrm{~cm}$ of the child. The experimenter held up the medal and said, "If you get this, you get a sticker, let's start you a pile" and a sticker was placed on the table. From here, the procedure was very similar to that of Experiment 1. Once the child was attending to the front, the experimenter said the child's name while simultaneously holding up the reward just above the centre of the task. The experimenter then baited the task, putting the reward either in the proximal or distal location. Within two seconds the experimenter operated either the pull-cord or lift-platform such that the platform swung up and the reward fell out onto the table, making it clear that the reward had been extracted. The child received 10 demonstrations. On demonstrations one, four, seven, and 10 the experimenter picked up a sticker and added it to the child's pile. These reward intervals were selected to sustain interest and to indicate that they could receive the reward, but a sticker was not given after each trial to keep the reward administration similar to the capuchins'. After the 10 demonstrations the experimenter rebaited the task in the same way and said, "Now it's your turn." The session time of three minutes started. If children were successful they were given up to a further four trials if this fell within the three minutes. The children that were not successful were rewarded with a sticker every one minute and two more stickers at the end of the session to keep in line with the procedure used with the capuchins. Thus, they received the same number of stickers as successful individuals. There was no second phase where the reward location was reversed. 
Accepted in the Journal of Comparative Psychology on 12 April 2017

\section{Coding}

476

A research assistant involved with the study and a second research assistant, blind to

477 the study's aims, separately coded eye gaze in the same way as for the capuchins: (a) the left

478 side of the box, where the means were located (means); (b) at the right side of the box, away

479 from the means (non- means'); (c) away from the box (away); or (d) unsure of where attention was focused (unsure). If coders did not agree, it was coded as unsure. All other behaviors were coded by a research assistant that was blind to the aims of the study and included: (a) First Touch; (b) Success; (c) Latency to success; (d) Means. These were defined in line with the capuchin study except latency to success was from when the reward was baited and the baiting door closed until the reward exited the box.

\section{Results}

Table 1 summarises the participant allocation and main findings. The following sections provide details of statistical analyses of the main hypotheses.

\section{Attention towards means}

The same stepwise multiple regressions as for the capuchin study were conducted to evaluate whether attending during demonstrations could be predicted by the location of the reward and the age of the child (Table 2). For attention toward means the only model accounting for significantly more variance than no predictors included both reward location and age $(p<.001)$. For attention toward non-means the only model accounting for significantly more variance than no predictors included location $(p<.001)$ and did not include age.

\section{Effects of reward contiguity on success}


Accepted in the Journal of Comparative Psychology on 12 April 2017

500 Overall, 135/180 individuals were successful in the three minutes; 68 children used pull-cord and 61 children used lift-platform, indicating no bias towards either method

502 (Binomial two-tailed, $p=.59$ ). Six used an alternative method of reaching their hand through 503 the exit slot and tipping the platform from this angle (distal conditions: no-demonstration $=$ 5042 , pull-cord $=2$, lift-platform $=1$, and proximal conditions: lift-platform $=1$ ). A logistic 505 regression analysis was conducted to evaluate whether success could be predicted by 506 presence of demonstration, reward location, and participant age. A test of the full model against a constant only model was statistically significant $\left(\mathrm{R}^{2}=.49, \mathrm{X}^{2}=72.3, p<.001\right.$; supplementary material Table A). Greater success was predicted by presence of a demonstration $(p<.001)$, a proximal reward $(p<.001)$, and increased age $(p<.01)$. Differences in latency to success were investigated, with unsuccessful children given a latency of 180s (three minutes). A stepwise multiple linear regression was conducted to evaluate whether reward location, demonstration (present or absent), and participant age were necessary to predict latency to success (supplementary material Table B). The model accounting for the most variance (39\%) included all three variables. Shorter latency to success was predicted by presence of a demonstration $(p<.001)$, a proximal reward $(p<$ $.001)$, and increased age $(p<.001)$.

Effects of reward contiguity on matching of demonstrated means

Of the 109/120 children that were successful following a demonstration, 98 (90\%) of them copied the demonstrated means. A logistic regression analysis was conducted to evaluate whether copying of the demonstrated means could be predicted by reward location and participant age. For a complete analysis, this was run twice, with unsuccessful children

523 either included (coded as having not copied the model) or excluded. When unsuccessful 524 children were included, the model that accounted for significantly more variance than no 
Accepted in the Journal of Comparative Psychology on 12 April 2017

525 predictors included both reward location $(\mathrm{B}=2.16, \mathrm{SE} \mathrm{B}=0.67, \operatorname{Exp}(\mathrm{B})=8.70, p<.01)$ and

526

527

528

529

530

531

532

533

534

535

536

537

538

539

540

541

542

543

544

545

546

547

548

549

\section{Additional analyses of behavioral details}

The majority (79.5\%) of the 166 of children who interacted with the task (excluding two participants where first touch was unclear) touched the means congruent location. A logistic regression analysis was conducted to evaluate whether means congruent first touch could be predicted by three factors: demonstration presence, reward location and participant age. A model excluding age, against a constant-only model, was statistically significant $\left(\mathrm{R}^{2}\right.$ $=.28, \mathrm{X}^{2}=33.21, p<.001$; supplementary material Table A). Means congruent first touch was predicted by presence of a demonstration $(p<.001)$ and a proximal reward $(p<.001)$. Participants were allowed up to five trials in three minutes and 129 children completed all five trials. The vast majority $(95.4 \%)$ only used one means throughout all trials.

\section{Comparison between children and capuchins}

Capuchins were significantly less likely to touch the means versus non-means side of the task than children (FET $p<.001)$ and significantly more likely to touch the side of the task where the reward was located than children (FET $p<.001$, see Figure 3). For both species demonstration attention and success was affected by reward location (see Figure 4). Irrespective of reward location, children were significantly more likely to copy the method demonstrated than capuchins (FET $p<.001)$. 
Accepted in the Journal of Comparative Psychology on 12 April 2017

550

\section{First touch}

551

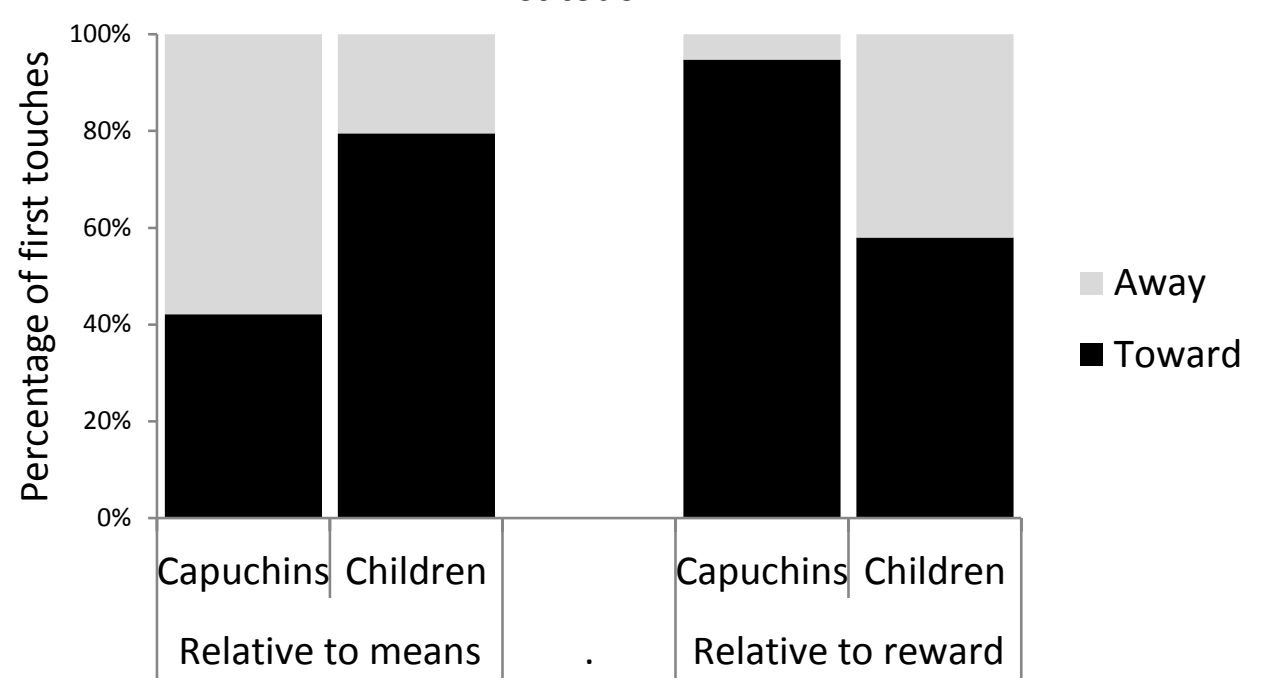

552 Figure 3: Location of first touches relative to task and food for children and capuchins 553 across all conditions. 


\section{A: Attention}
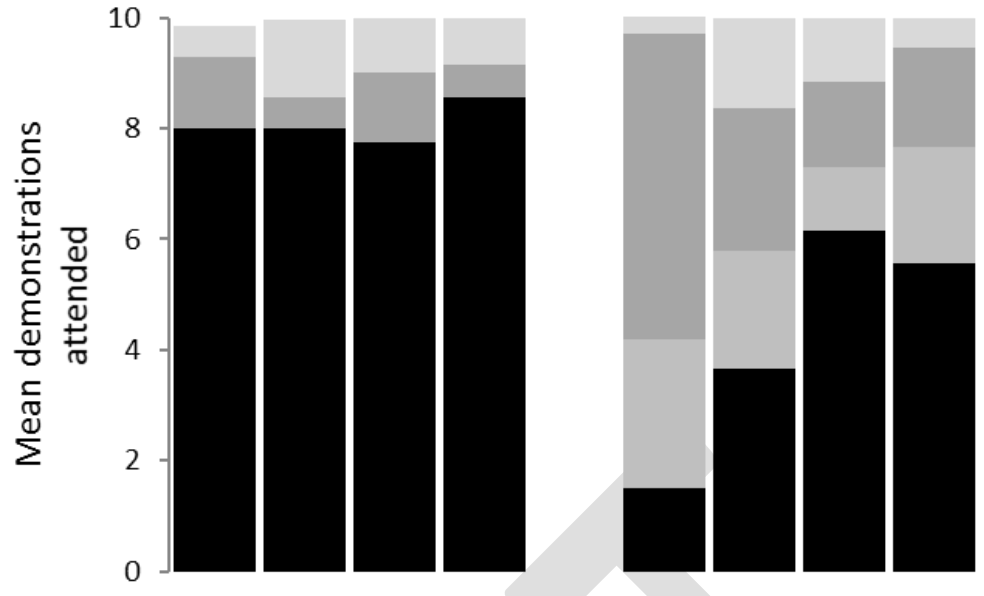

$\square$ Away

Unsure

Away from Means

- Toward Means

\section{B: Success}

C: Means of success
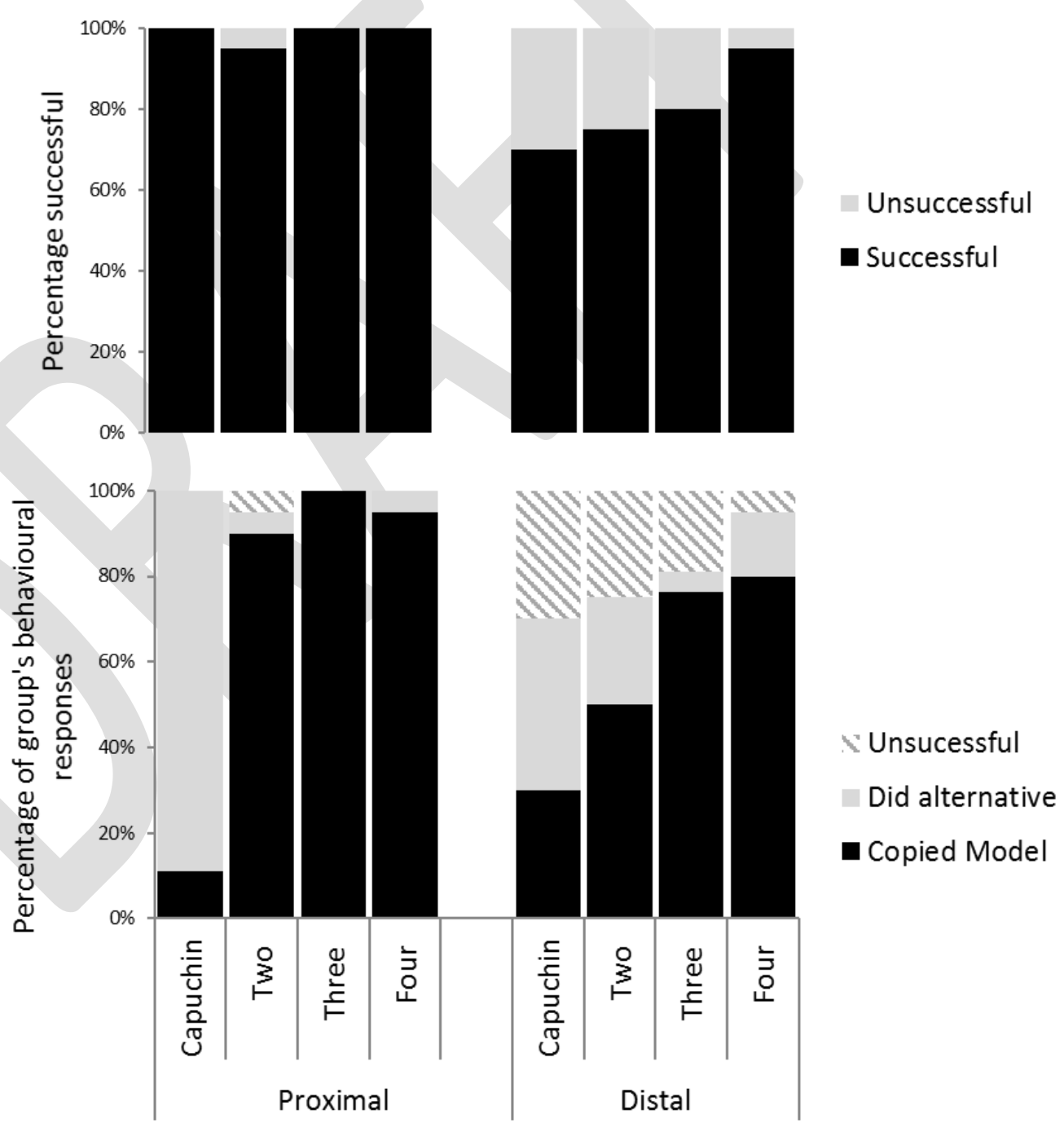

556 Figure 4: Summary of behavioral responses for individuals that witnessed a social

557 demonstration. Two/three/four refer to ages of children in years 
Accepted in the Journal of Comparative Psychology on 12 April 2017

558

559

560

561

562

563

564

565

566

567

568

569

570

571

572

573

574

575

576

577

578

579

580

581

582

\section{Discussion}

The current study explicitly manipulated reward location, relative to the means of obtaining the reward, to test the hypothesis that spatial contiguity between a reward and the means of accessing that reward affects social learning. We found evidence that, in two very different species of primate, reward location had a significant impact upon visual attention towards demonstrations of means and task success. Reward location also affected copying of the demonstrated means although this effect was shaped by species and age. In the following sections we discuss these results and their implications for our understanding of the importance of spatial contiguity in social learning, for behavioral convergences and divergences between children and capuchins, and developmental changes in children.

\section{Convergent behavioral patterns}

For both species, the location of the reward had a significant effect on individual's attention towards the task during social demonstration of the means. If the reward was located proximal to the means, the majority of participants attended to this direction during demonstration. Conversely, when the reward was located at the distal location to the means, there was reduced attention towards the demonstrations and increased attention towards the distal reward. We take this as the first evidence that the sight of a reward stimulus proves to be an overpowering and distracting stimulus during social demonstrations. The distal reward location reduced attention towards social information which likely impaired social learning. For both species the location of the reward had a significant effect on levels of success. When the reward was proximal to the means the majority of individuals were successful whereas fewer individuals were successful when the reward was distal to the means, although this difference was only significant for the children. The detrimental effect of a distal reward to means location was evident in the increased latency to success for both 
Accepted in the Journal of Comparative Psychology on 12 April 2017

583

584

585

586

587

588

589

590

591

592

593

594

595

596

597

598 Divergent behavioral patterns

599

600

601

602

603

604

605

606

607

\section{Divergent behavioral patterns}

species. The relationship between measures of success and social learning are unclear because reward and means spatial contiguity was consistent in both the demonstration and test phases. Consequently, the location of reward during the test phase, rather than during demonstration, could have driven such an effect. Indeed, that: (a) two capuchins with no social information solved the task quickly; (b) previously successful capuchins in the proximal condition often became slower when the reward moved to a distal location; and (c) reward location affected success for no-demonstration children, all suggest that reward location may be sufficient for influencing success. Thus, the current study supports results showing that spatial contiguity affects non-social associative learning in animals (Kushnir \& Gopnik, 2007; Polidora \& Fletcher, 1964; Wasserman \& Miller, 1997). However, differing success levels between children in the demonstration and no-demonstration conditions indicated that the reward location during demonstration did affect their success. To further assess the impact of reward location upon social learning we investigated copying of the specific demonstrated means, which we address in the next section.

Comparative studies of humans with other species can be problematic as divergent behaviour may be due to the different methods used (Boesch, 2007) although, as Tomasello \& Call (2008) argue, methodological differences sometimes represent functional equivalence more so than exact matching. We acknowledge both sides of this debate and avoided an explicit comparison of the two species. Hence, the species took part in two different experiments and statistical comparisons were largely within each species. However, we feel it is appropriate to comment upon some of the behavioral divergences preceded by an outline of the primary methodological differences concerning: the reward; the species (mis)matching of the demonstrator; the presence of a primary caregiver; and the response time. 
Accepted in the Journal of Comparative Psychology on 12 April 2017

608

609

610

611

612

613

614

615

616

617

618

619

620

621

622

623

624

625

626

627

628

629

630

631

632

First, the reward differed as we wanted a high value reward for both species. Food preference tests indicated that a peanut was the highest value reward for the capuchins. We were not able to offer a peanut to the children due to potential allergies. Thus, a sticker was deemed an equivalent high value reward. However, s sticker did not reliably exit the apparatus so a gold plastic token was used. Second, the experimenter (demonstrator) for every experiment was a human; thus the children had an unknown conspecific demonstrator whereas the capuchins had a familiar non-conspecific demonstrator. A human was required to ensure appropriate demonstration control. Third, presence of a primary caregiver and fourth, maximum response time differences were a product of aiming for equivalence in terms of comfort. These capuchins are used to isolating and participating in experiments for up to 15 minutes and those capuchins that were unsuccessful continued to interact with the task for the full five minutes. Conversely, the children were not used to isolating and participating in experiments and we did not want to cause undue stress with extended response times. We found, as with previous work (e.g., Wood et al., 2013), that three minutes allowed sufficient time for testing, and children that were unsuccessful often ceased interacting with the task in under two minutes.

A significant behavioral divergence was in the copying of the demonstrated means.

Children generally copied the specific means demonstrated although a distal reward location significantly reduced rates of copying. We take this as the first evidence that reward and means proximity during demonstrations affects social learning in young children. The evidence of such an effect with capuchins was far less clear. Capuchins in the proximal condition showed a means choice that was significantly different to chance whereas those in the distal condition did not. However, surprisingly and puzzlingly, the means choice of eight of the nine capuchins in the proximal condition was opposite to the means demonstrated. We tentatively suggest that capuchins in the proximal condition were attending to the means, but 
Accepted in the Journal of Comparative Psychology on 12 April 2017

633 counter to our intentions, the demonstrator's actions made the alternative means more

634

635

salient. In reviewing videos, we noted that that in the pull-cord demonstration the demonstrator's hand partially masked the grasped knobble, whereas the platform rising and the entrance hole used for lift-platform remain clearly visible. Conversely, during the liftplatform demonstration the demonstrator's hand potentially masked the entrance hole of this method whereas the alternative means remained clearly visible. Therefore, the means opposite to the one demonstrated may have been inadvertently more salient to the capuchins. A difference in species relevance for the two species may have affected the salience of the social demonstration (Boesch, 2007). Human hands may mean fundamentally different things to a capuchin versus a human child, potentially explaining why the reversal effect occurred with the capuchins but not the children. Thus, the capuchins may have been replicating these movements of components of the box (object movement centered) rather than the actions of the demonstrator (model movement centered, Whiten et al., 2004).

A second behavioral divergence was that all but one of the capuchins' first touches corresponded to the location of the reward whereas children's first touches were far more likely to correspond to the location of the means. The difference in reward may have caused this species difference; the food may have been far more salient for the capuchins and appealing than the secondary reinforcer token for the children. However, previous research indicates that children are very motivated to obtain a token that leads to the primary reinforcer of a sticker (e.g., Wood et al., 2012). Although a secondary reinforcer may be less appealing and thus affect attention and prepotent responses to reach for it, we did not see any evidence that children were less interested in attending to the apparatus or demonstrations.

We believe that the current study is a case where the reward was different but the functional equivalence of the reward was equally salient (Tomasello \& Call, 2008). Another explanation of this first-touch divergence is that capuchins had less understanding of the task 
Accepted in the Journal of Comparative Psychology on 12 April 2017

658

659

660

661

662

663

664

665

666

667

668

669

670

671

672

673

674

675

676

677

678

679

680

681

682

material than the children and tried to access the reward through the transparent plastic.

However, these capuchins have vast experience of transparent plastic in their enclosure, their frequently used enrichment devices, and in previous apparatus. Alternatively, capuchins have less inhibitory control and so reacted to a prepotent response to reach for food, as is species typical of capuchins (Amici et al., 2008; Beran et al., 2016). The current study cannot confidently distinguish between these explanations but they are ripe for further exploration. The third notable species difference relates to solution conservatism. Although the majority of the capuchins used both means, children generally showed high levels of conservatism towards one means. Solution conservatism versus flexibility has been investigated in several other primate species (e.g., chimpanzees: Hopper, Schapiro, Lambeth, \& Brosnan, 2011; vervet monkeys: van de Waal, Borgeaud, \& Whiten (2013); and squirrel monkeys: Cladiere et al., 2013) and the current study shows that brown capuchin monkeys are able to flexibly switch between different means. Conversely, only six children used multiple methods in line with other research demonstrating high method conservatism in children following social demonstrations (Hopper et al., 2010). However, the level of conservatism in the no-demonstration conditions is surprising given that previous work with five-year-olds has shown that personal exploration may encourage multiple-method adoption (Wood, Flynn, \& Kendal, 2013). An age difference may explain these differences. The results suggest that social information was not the reason for means conservatism in the current study and therefore cannot explain why children were markedly more conservative than capuchins.

\section{Developmental changes}

The age of a child was a significant predictor of: attention towards means and nonmeans sides of the task; success; and copying of the demonstrated means (when including 
Accepted in the Journal of Comparative Psychology on 12 April 2017

683

684

685

686

687

688

689

690

691

692

693

694

695

696

697

698

699

700

701

702

703

704

705

706

707

unsuccessful children). Although four-year-olds were somewhat distracted by the reward during the demonstration phase they were still able to attend to social information sufficiently to be successful relatively quickly and to copy the demonstrated means.

Conversely, younger children were distracted by the reward, were less successful, and showed less reproduction of the demonstrated means. Previous demonstrations by a human conspecific using a transparent apparatus have not shown many development differences in the copying of the means between ages two- to five-years-old (Flynn, 2008; Flynn \& Whiten, 2008a \& 2008b; Horner \& Whiten, 2005; McGuigan et al., 2007; McGuigan \& Whiten, 2009). However, several of these studies that used the same apparatuses have revealed developmental differences in some behavioral responses. For example, McGuigan et al. (2007) found that three-year-olds were less likely to copy the demonstrated means than five-year-olds when the demonstration was via a video. The authors argue that for the younger children "the degraded information led to a differential focus on the task outcome, as opposed to the actions of the model, resulting in an emulative approach." (p. 362). The current study suggests that differences in the presentation of the means, as with the capuchins, can affect younger children's attention more than older children's. This in turn leads older children to copy the form of an action (model movement centred), and younger children to copy the form of a caused object movement (object movement centred). Likewise, McGuigan \& Whiten (2009) compared their results with two- and threeyear-olds with that of McGuigan et al.'s (2007) study and found that in relation to copying of causally irrelevant tool insertions within the means, age increase corresponded to an increase in copying unnecessary demonstrated tool insertions and insertion method. This difference was greatest when the reward was in an opaque chute held in a transparent versus opaque apparatus. The authors suggest that the younger children may have "focused their attention differently from the older children, with the 3- and 5-year-olds focusing their attention on the 
Accepted in the Journal of Comparative Psychology on 12 April 2017

708

709

710

711

712

713

714

715

716

717

718

719

720

721

722

723

724

725

726

727

728

729

730

731

732

actions of the model and the majority of the younger children focusing either on the results of the task or on reproducing the movements of parts of the box" (p. 379). We suggest that, irrespective of box transparency, five-year-old children focus their attention on both the actions of the model and the movement of parts affected. Conversely, and particularly when an apparatus is transparent and the reward's location is salient, younger children are distracted by the reward and so attend less to the model's actions. We speculate that this may be a likely explanation for the developmental change towards inefficient copying, rather than any developmental changes relating to strategies concerning what to copy.

A similar explanation could apply to an increase in chimpanzee's copying of causally irrelevant tool insertions when the apparatus involved was opaque rather than transparent (Horner \& Whiten, 2005). Chimpanzees presented with the transparent apparatus may have been distracted by the reward location and thus primarily attended to demonstrated actions in the area proximal to the reward, which they copied, while ignoring demonstrated actions distal to the reward which they failed to copy. We believe further investigation of this area is important in our understanding of the phenomena of inefficient copying thus far documented in older children and adults but not in younger children and other species.

\section{Implications for social learning research}

The current study has been the first to demonstrate significant effects of reward location on attention towards, and social learning from, demonstrations by others. It has highlighted how a small change in experimental and apparatus design can have a marked impact on behavioral responses associated with social learning. As noted in our introduction, capuchin social learning has appeared most evident and sophisticated when a single reward was protected by an opaque defense and where the action upon that defense was proximal to the reward. The results from the current study offer an explanation of why this might occur. 
Accepted in the Journal of Comparative Psychology on 12 April 2017

733 Apparent differences in evidence for social learning in multiple experiments with capuchins

734

735

736

737

738

739

740

741

742

743

744

745

746

747

748

749

750

751 may instead reflect differences in spatial contiguity between reward and means. The same may also be true of apparent species differences where different apparatuses have been used.

We would urge future work with all species to consider that seemingly minor changes in apparatus design can have a marked impact and that tasks which are opaque -the common occurrence in the wild - may offer the greatest chance of demonstrating an animal's social learning abilities.

The current study may aid an understanding of social learning differences between species and across development insofar as demonstrating that capuchins and two-year-old children are more easily distracted away from social information by a reward than four-yearold children. We are not claiming this is the only explanation for species and developmental differences in social learning, but such effects contribute to a greater understanding of social learning and the distinctiveness of humans' social learning abilities. From as young as fouryears-old, children are able to attend to socially demonstrated solutions and reproduce these solutions with high fidelity (here and McGuigan et al., 2007). Such high fidelity transmission of behavioral traits between individuals has been proposed to be of key importance to the evolution of cumulative culture (Boyd \& Richerson, 1996; Tomasello, 1999). Research that cannot only describe but explain differences in copying behaviors may help to unlock the key to mankind's success. 
Accepted in the Journal of Comparative Psychology on 12 April 2017

752

753

754

755

756

757

758

759

760

761

762

763

764

765

766

767

768

769

770

771

772

773

774

775

\section{References}

Anderson, D. R., \& Levin, S. R. (1976). Young children's attention to" Sesame Street". Child Development, 47(3), 806-811.

Amici, F., Aureli, F., \& Call, J. (2008). Fission-fusion dynamics, behavioral flexibility, and inhibitory control in primates. Current Biology, 18(18), 1415-1419.

Aplin, L. M., Farine, D. R., Morand-Ferron, J., Cockburn, A., Thornton, A., \& Sheldon, B. C. (2015). Experimentally induced innovations lead to persistent culture via conformity in wild birds. Nature, 518(7540), 538-541.

Beran, M. J., Perdue, B. M., Rossettie, M. S., James, B. T., Whitham, W., Walker, B., Futch, S. E., \& Parrish, A. E. (2016). Self-control assessments of capuchin monkeys with the rotating tray task and accumulation task. Behavioural Processes, 129, 68-79.

Bandura, A., \& Walters, R. H. (1977). Social learning theory. New York, NY: General Learning Press.

Boyd, R., \& Richerson, P. J. (1996). Why culture is common, but cultural evolution is rare. Proceedings-British Academy, 88, 77-94.

Bramlett, J. L., Perdue, B. M., Evans, T. A., \& Beran, M. J. (2012). Capuchin monkeys (Cebus apella) let lesser rewards pass them by to get better rewards. Animal Cognition, 15(5), 963-969.

Carpenter, M., Akhtar, N., \& Tomasello, M. (1998). Fourteen-through 18-month-old infants differentially imitate intentional and accidental actions. Infant Behavior and Development, 21(2), 315-330.

Claidière, N., Messer, E. J., Hoppitt, W., \& Whiten, A. (2013). Diffusion dynamics of socially learned foraging techniques in squirrel monkeys. Current Biology, 23(13), 1251-1255. 
Accepted in the Journal of Comparative Psychology on 12 April 2017

776 Crast, J., Hardy, J. M., \& Fragaszy, D. (2010). Inducing traditions in captive capuchin

777

778

779

780

781

782

783

784

785

786

787

788

789

790

791

792

793

794

795

796

797

798

799

800 monkeys (Cebus apella). Animal Behaviour, 80(6), 955-964.

Custance, D., Whiten, A., \& Fredman, T. (1999). Social learning of an artificial fruit task in capuchin monkeys. Journal of Comparative Psychology, 113(1), 13.

Dawson, B. V., \& Foss, B. M. (1965). Observational learning in budgerigars. Animal Behaviour, 13(4), 470-474.

Dindo, M., Thierry, B., \& Whiten, A. (2008). Social diffusion of novel foraging methods in brown capuchin monkeys (Cebus apella). Proceedings of the Royal Society B: Biological Sciences, 275(1631), 187-193.

Dindo, M., Thierry, B., de Waal, F., \& Whiten, A. (2010). Conditional copying fidelity in capuchin monkeys (Cebus apella). Journal of Comparative Psychology, 124(1), 29.

Evans, T. A., Beran, M. J., Chan, B., Klein, E. D., \& Menzel, C. R. (2008). An efficient computerized testing method for the capuchin monkey (Cebus apella): Adaptation of the LRC-CTS to a socially housed nonhuman primate species. Behavior Research Methods, 40(2), 590-596.

Flynn, E. (2008). Investigating children as cultural magnets: do young children transmit redundant information along diffusion chains? Philosophical Transactions of the Royal Society of London B: Biological Sciences, 363(1509), 3541-3551.

Flynn, E. \& Smith, K. (2012) Investigating the mechanisms of cultural acquisition. Social Psychology, 43(4), 185-195.

Flynn, E., \& Whiten, A. (2008a). Imitation of hierarchical structure versus component details of complex actions by 3-and 5-year-olds. Journal of Experimental Child Psychology, 101(4), 228-240.

Flynn, E., \& Whiten, A. (2008b). Cultural transmission of tool use in young children: A diffusion chain study. Social Development, 17(3), 699-718. 
Accepted in the Journal of Comparative Psychology on 12 April 2017

801 Fragaszy, D. M., \& Visalberghi, E. (1989). Social influences on the acquisition of tool-using 802 behaviors in tufted capuchin monkeys (Cebus apella). Journal of Comparative

803 Psychology, 103(2), 159.

804

Fragaszy, D. M., \& Visalberghi, E, \& Fedigan, L. M. (2004). The complete capuchin: the biology of the genus Cebus. Cambridge, UK: Cambridge University Press.

Fredman, T., \& Whiten, A. (2008). Observational learning from tool using models by human-reared and mother-reared capuchin monkeys (Cebus apella). Animal

808 Cognition, 11(2), 295-309.

Giraldeau, L. A., \& Lefebvre, L. (1987). Scrounging prevents cultural transmission of foodfinding behaviour in pigeons. Animal Behaviour, 35(2), 387-394.

Heyes, C. M. (1994). Social learning in animals: categories and mechanisms. Biological Reviews, 69(2), 207-231.

813 Horner, V., \& Whiten, A. (2005). Causal knowledge and imitation/emulation switching in chimpanzees (Pan troglodytes) and children (Homo sapiens). Animal cognition, 8(3), 164-181.

Horner, V., Whiten, A., Flynn, E., \& de Waal, F. B. (2006). Faithful replication of foraging techniques along cultural transmission chains by chimpanzees and

Hopper, L. M., Flynn, E. G., Wood, L. A., \& Whiten, A. (2010). Observational learning of tool use in children: Investigating cultural spread through diffusion chains and learning mechanisms through ghost displays. Journal of Experimental Child Psychology, 106(1), 82-97. in chimpanzees and children studied through 'ghost'conditions. Proceedings of the Royal Society of London B: Biological Sciences, 275(1636), 835-840. 
Accepted in the Journal of Comparative Psychology on 12 April 2017

826

827

828

829

830

831

832

833

834

835

836

837

838

839

840

841

842

843

844

845

846

847

848

849

850

Hopper, L. M., Schapiro, S. J., Lambeth, S. P., \& Brosnan, S. F. (2011). Chimpanzees' socially maintained food preferences indicate both conservatism and conformity. Animal Behaviour, 81(6), 1195-1202.

Kochanska, G., Murray, K., Jacques, T. Y., Koenig, A. L., \& Vandegeest, K. A. (1996). Inhibitory control in young children and its role in emerging internalization. Child Development, 490-507.

Kushnir, T., \& Gopnik, A. (2007). Conditional probability versus spatial contiguity in causal learning: Preschoolers use new contingency evidence to overcome prior spatial assumptions. Developmental Psychology, 43(1), 186.

Leonardi, R., Buchanan-Smith, H. M., Dufour, V., MacDonald, C., \& Whiten, A. (2010). Living together: behavior and welfare in single and mixed species groups of capuchin (Cebus apella) and squirrel monkeys (Saimiri sciureus). American Journal of Primatology, 72(1), 33-47.

Macdonald, C., \& Whiten, A. (2011). The 'Living Links to Human Evolution' Research Centre in Edinburgh Zoo: a new endeavour in collaboration. International Zoo Yearbook, 45(1), 7-17.

McGuigan, N., Whiten, A., Flynn, E., \& Horner, V. (2007). Imitation of causally opaque versus causally transparent tool use by 3 -and 5-year-old children. Cognitive Development, 22(3), 353-364.

McGuigan, N., \& Whiten, A. (2009). Emulation and "overemulation" in the social learning of causally opaque versus causally transparent tool use by 23 -and 30 -montholds. Journal of Experimental Child Psychology, 104(4), 367-381.

Perry, S. (2011). Social traditions and social learning in capuchin monkeys (Cebus). Philosophical Transactions of the Royal Society B: Biological Sciences, 366(1567), 988-996. 
Accepted in the Journal of Comparative Psychology on 12 April 2017

851 Perry, S., Baker, M., Fedigan, L., Gros-Louis, J., Jack, K., MacKinnon, K. C., ... \& Rose, L.

852

853

854

855

856

857

858

859

860

861

862

863

864

865

866

867

868

869

870

871

872

873

874 (2003). Social conventions in wild white-faced capuchin monkeys. Current Anthropology, 44(2), 241-268.

Polidora, V. J., \& Fletcher, H. (1964). An analysis of the importance of SR spatial continguity for proficient primate discrimination performance. Journal of Comparative and Physiological Psychology, 57(2), 224.

Ruff, H. A., \& Capozzoli, M. C. (2003). Development of attention and distractibility in the first 4 years of life. Developmental Psychology, 39(5), 877.

Thornton, A., \& Malapert, A. (2009). Experimental evidence for social transmission of food acquisition techniques in wild meerkats. Animal Behaviour, 78(2), 255-264.

Tomasello, M. (1996). Do apes ape? In C. M. Heyes \& B. G. Galef (Eds), Social learning in animals: The roots of culture (pp. 319-346), London, UK: Academic Press.

Tomasello, M. (1999). The cultural origins of human cognition. Cambridge, MA:Harvard University Press.

Whiten, A., \& Ham, R. (1992). Reappraisal of a century of research. Advances in the Study of Behavior, 21, 239.

Whiten, A., Horner, V., Litchfield, C. A., \& Marshall-Pescini, S. (2004). How do apes ape? Animal Learning \& Behavior, 32(1), 36-52.

Whiten, A., Horner, V., \& De Waal, F. B. (2005). Conformity to cultural norms of tool use in chimpanzees. Nature, 437(7059), 737-740.

van de Waal, E., Borgeaud, C., \& Whiten, A. (2013). Potent social learning and conformity shape a wild primate's foraging decisions. Science, 340(6131), 483-485.

van de Waal, E., Renevey, N., Favre, C. M., \& Bshary, R. (2010). Selective attention to philopatric models causes directed social learning in wild vervet monkeys. 
Accepted in the Journal of Comparative Psychology on 12 April 2017

875

876

877 Visalberghi, E. (1993). Capuchin monkeys: A window into tool use in apes and humans. In

878

879

880

881

882

883

884

885

886

Proceedings of the Royal Society of London B: Biological Sciences, 277(1691), 21052111.

K. Gibson \& T. Ingold (Eds.), Tools, language, and cognition in human evolution (pp. 138-150). Cambridge, UK: Cambridge University Press.

Wasserman, E. A., \& Miller, R. R. (1997). What's elementary about associative learning? Annual Review of Psychology, 48(1), 573-607.

Wood, L. A., Harrison, R. A., Lucas, A. J., McGuigan, N., Burdett, E. R., \& Whiten, A. (2016). "Model age-based" and "copy when uncertain” biases in children's social learning of a novel task. Journal of Experimental Child Psychology, 150, 272-284.

Wood, L. A., Kendal, R. L., \& Flynn, E. G. (2013). Whom do children copy? Model-based biases in social learning. Developmental Review, 33(4), 341-356. 
Accepted in the Journal of Comparative Psychology on 12 April 2017

\section{Supplementary Material}

888

889 Table A; Summary of binomial logistic regression analysis for variables predicting success

890 and location of first touch (children).

\begin{tabular}{lllllll}
\hline & Success & & \multicolumn{3}{c}{ Means congruent first touch } \\
\hline Variables & B & SE B & $\operatorname{Exp}(\mathrm{B})$ & $\mathrm{B}$ & SE B & $\operatorname{Exp}(\mathrm{B})$ \\
Demonstration by model & 3.20 & 0.52 & $24.49 * * *$ & -1.81 & 0.44 & $0.16^{* * *}$ \\
Reward Location & 1.84 & 0.50 & $6.28 * * *$ & -1.71 & 0.49 & $0.18^{* * *}$ \\
Age in months & 0.07 & 0.02 & $1.07 * *$ & -0.01 & 0.02 & 0.99 \\
Nagelkerke's R & & & .49 & & & .28 \\
$\mathrm{X}^{2}$ & & & $72.3 * * *$ & & & $33.21 * * *$ \\
\hline
\end{tabular}

891

$p<.05 . * * p<.01 . * * * p<.001$. Means congruent first touch no $=0$, yes $=1$. Demonstration

892 by model; $n o=0$, yes $=1$. Reward location; proximal $=1$, distal $=0$

893

894

895 Table B; Summary of multiple linear regression analysis for variables predicting latency to 896 success.

\begin{tabular}{lllr}
\hline & Success & & 897 \\
\hline Variables & B & SE B & Beta 898 \\
Demonstration by model & -82.54 & 9.32 & $-0.52 * 899$ \\
Reward Location & -37.68 & 8.79 & $-0.25 * 900$ \\
Age in months & -1.70 & 0.43 & $-0.23 * 901$ \\
$\mathrm{R}^{2}$ & & & $.39 \quad 902$ \\
$\mathrm{~F}$ & & $37.28 * 9.96$ \\
\hline
\end{tabular}

$905 * * * p<.001$. Demonstration by model; $n o=0$, yes $=1$. Reward location; proximal $=1$, distal $906=0$. 